\title{
Stem Cell Therapy for Female Urinary Incontinence
}

\author{
Kelly L. Kantartzis • Pamela A. Moalli
}

Published online: 19 June 2013

(C) Springer Science+Business Media New York 2013

\begin{abstract}
Both stress and urge urinary incontinence affect a significant proportion of women, yet the treatment options currently available may lack long-term effectiveness or may be associated with significant adverse events limiting their use. Thus, novel treatment options are needed. Stem cells, with the ability to transform into multiple cell types or to self-renew, have been proposed as a potential treatment option for both stress and urge incontinence. The majority of research has been performed in animal models and has shown that urethral or intradetrusor injection of various types of stem cells improves surrogate markers of incontinence. Although many of these studies have shown promising effects, significant research is still needed before translating these findings into clinical practice.
\end{abstract}

Keywords Urinary incontinence $\cdot$ Stress urinary incontinence $\cdot$ Urge urinary incontinence $\cdot$ Stem cells . Regenerative medicine

\section{Introduction}

Urinary incontinence is a highly prevalent condition associated with significant patient morbidity and economic costs [1, 2]. In their lifetime, as many as $35 \%$ of women will experience stress urinary incontinence (SUI), the involuntary leakage of urine with laughing, coughing, or sneezing, whereas as many as $46.9 \%$ of women will experience urge urinary incontinence (UUI), the involuntary leakage with urge $[2,3]$. Costs in the United States alone in the year 2000 have been estimated to be at least $\$ 20$ billion [4]. As the population continues to age, it is

\footnotetext{
K. L. Kantartzis $(\varangle) \cdot$ P. A. Moalli

Division of Urogynecology and Reconstructive Pelvic Surgery, Department of Obstetrics, Gynecology, and Reproductive Sciences, Magee Womens Hospital, University of Pittsburgh Medical Center, 300 Halket Street, Pittsburgh, PA 15213, USA

e-mail: gerschultzkl@upmc.edu

P. A. Moalli

e-mail: pmoalli@mail.magee.edu
}

anticipated that both the number of patients seeking care as well as the costs will continue to rise [5].

Standard treatment options for SUI include pelvic floor physical therapy, incontinence pessaries, or surgical options, such as periurethral bulking injections, midurethral slings, or retropubic urethropexies. Periurethral or transurethral injections, in which a bulking agent, such as calcium hydroxylapatite, is injected near or within the urethra, have relatively low success rates reported at approximately $40 \%$ for cure and $70-80 \%$ for improvement [6]. Patients often need multiple injections given the transient effectiveness. Complications are generally mild and include urinary retention, infection, and pain; however, more serious events, including abscess formation, extrusion into the urethra, and hypersensitivity to the injected material, have been reported $[6,7]$. Finally, concern for particle migration after injection highlights additional problems with this treatment option [8]. Midurethral slings have very high reported success rates up to $80.8 \%$, but patients may have reservations about the placement of transvaginal mesh [9]. While providing superior results, mesh is associated with multiple risks including mesh exposure (rates ranging from $0.6-5.4 \%$ after midurethral sling), pelvic pain, dyspareunia, infection, vaginal discharge, sinus tract formation, and the need for reoperation [10]. Thus, the many limitations and concerns with the use of mesh reinforce that novel treatment options and materials are warranted.

First-line treatment of UUI often includes antimuscarinic drugs in combination with behavioral modifications. Unfortunately, $35.1 \%$ of patients who try these drugs will never have their prescription refilled, likely due to lack of efficacy or intolerable side effects [11]. Additional therapies for UUI include intravesical botulinum toxin injection, sacral neuromodulation, and percutaneous tibial nerve stimulation with reported success rates of $60-85 \%, 67-80 \%$, and $54.5 \%$, respectively [12-15]. Botulinum toxin injection is associated with a high rate of urinary retention, underscoring the need for patients to be counseled about the risks and potential need for self-catheterization. Similarly, rates of urinary tract infection have been noted to be as high as $31 \%$ [16]. Lastly, the effects of botulinum toxin are temporary 
with most women needing additional therapy within 1 year [17]. Sacral neuromodulation is a more invasive option involving the placement of an implantable pulse generator and permanent electrodes to stimulate the S3 sacral nerve root. It is associated with a high rate of reoperation (25-30.3\%), infection (5-7.9\%), and pain (9-27\%) and thus may be associated with significant morbidity [14, 18-21].

Given the variability in efficacies, the potential side effects, and the lack of options for women who have poor smooth muscle integrity, absence of coaptation, and have failed conventional therapies, researchers have been studying stem cell therapy as a potential therapeutic option for urinary incontinence. This review provides a brief overview of stem cell therapy and discusses the relevant literature regarding the use of various stem cells for treatment of both stress and urge urinary incontinence.

\section{Stem Cell Therapy}

During the past 60 years, significant advances have been made in the field of stem cells and tissue engineering. Stem cells are unique in that they have the potential of replicating, differentiating into various different cell types, and forming a population from just one cell. Stem cells may be totipotent, pluripotent, multipotent, or unipotent with the ability to differentiate into any cell type, including embryonal, any of the three germ cell layers, a select few cell types, or only self-renew, respectively [22]. They may be obtained from various sources, such as bone marrow, adipose tissue, or embryos, which often define their potency.

Embryonic stem cells, derived from the inner cell mass of embryos in the blastocyst stage, are ideal for therapy given their pluripotency and ability to proliferate undifferentiated for many passages [23]. With the benefits of pluripotency also come the risks of immunorejection and teratoma or teratocarcinoma formation. Human-derived embryonic stem cells, often obtained from embryos created with assisted-reproductive technology, have additional ethical concerns, which have limited their use [24]. However, Zhang et al. found that embryonic stems cells derived from arrested embryos retained multiple pluripotency markers similar to those obtained from developing embryos [25]. Thus, arrested embryos may be a source of stem cells with less ethical limitations. Other gestational tissues contain stem cells, such as amniotic fluid, placenta, and umbilical cord blood, and are less controversial. Amniotic fluid-derived stem cells, with a short doubling time of 36 hours, are able to differentiate into all three germ cell types [26]. Likewise, hematopoietic stem cells have been isolated from umbilical cord blood, whereas the Wharton's jelly of the umbilical cord contains mesenchymal stem cells [27].

Adult-derived stem cells are not pluripotent, but some still maintain the ability to differentiate into different cell types [22]. Similarly, adult cells can be reprogrammed by transduction with retroviruses containing genes that improve growth potential and dedifferentiation to form induced pluripotent cells. Mesenchymal stem cells, which maintain multipotency, have been derived traditionally from bone marrow, but also may be derived from skeletal muscle, adipose tissue, and the majority of adult tissue types [28]. They are ideal candidates for regenerative therapy given the low risk for malignant differentiation, the ability for autologous transfer and thus elimination of the risk of rejection, and the absence of ethical controversy as seen in embryonic stem cells [29••]. Indeed, the majority of stem cell research in the lower urinary tract focuses on mesenchymal stem cells.

\section{Stress Urinary Incontinence and Autologous Connective Tissue Cells}

Urethral bulking, periurethral or transurethral injection of bulking agents to improve urethral coaptation, has been traditionally performed with nonimmunogenic and biocompatible substances, such as bovine collagen, calcium hydroxyapatite, or silicon particles with various degrees of success [30]. As potentially more efficacious options, various connective tissue cells have been studied as possible bulking agents [31, 32]. In one study, 32 women with intrinsic sphincter deficiency diagnosed by a Valsalva leak point pressure of less than $90 \mathrm{~cm} \mathrm{H}_{2} 0$ received a single autologous ear chondrocyte periurethral or transurethral injection distal to the bladder neck [31]. At 1 year follow-up, 16 patients (50\%) were dry, whereas 10 reported sustained improvement $(31.3 \%)$. Of the 22 women with repeat leak point pressures, $9(40.9 \%)$ had increases greater than $30 \mathrm{cmH}_{2} \mathrm{O}$. Few women reported adverse events and these mostly included urinary tract infections, vaginal bleeding, dysuria, urinary frequency, and urinary retention.

In a much larger study, including 123 women with urodynamically proven SUI, women received transurethral injection of autologous myoblasts and fibroblasts obtained from a biceps muscle biopsy [33]. The fibroblasts were mixed with collagen to prevent site migration. Seventy-nine percent (94/119) of the women were completely continent at one year, with improvement in Incontinence Scores from a median of 6 to 0 . An additional 16 women reported substantial improvement. Periurethral surface electromyography measurements also were improved with increased rhabdosphincter contractility at rest $(34.0 \pm 11.0$ to $45.1 \pm 15.0 \mu \mathrm{V})$ and with voluntary contraction $(43.1 \pm 11.8$ to $55.4 \pm 15.3 \mu \mathrm{V})$. No adverse events were reported; however, the authors note that much further study is needed including multicenter studies and long-term follow-up to confirm this therapy as a potential treatment for SUI. A smaller study by the same authors, including 20 women with SUI treated with transurethral injection of myoblasts and fibroblasts, revealed that $16(80 \%)$ still reported cure at 2 years of follow-up [32]. 


\section{Stress Urinary Incontinence and Muscle-Derived Stem Cells}

A significant amount of research has focused on musclederived stem cells (MDSC) in the lower urinary tract. Myoblasts can be injected into either urethral or bladder wall tissue with subsequent formation of myotubes in the smooth muscle layer [34]. After formation of myotubes, these cells become postmitotic and thus have a low likelihood for growth or spread. In contrast to myoblasts, MDSC have the ability to survive longer than 48 hours [35]. Yokoyama et al. demonstrated that autologous MDSC obtained from gastrocnemius muscle biopsies from Sprague-Dawley rats and injected into the urethra or bladder were able to survive and differentiate into myotubes and myofibers [36]. When they compared this injection to that of a bovine collagen injection, rats injected with MDSC had persistence of the injected periurethral nodules at 30 days while those with collagen injection had significantly smaller nodules indicating loss of injected mass. They postulated that the potential effects of MDSC were not only the ability of these cells to differentiate into myotubes but that they also may contain satellite cells with the ability to differentiate into various cell types based on the surrounding environment. Other theories of mechanism of action include promotion of innervation and improvement in tissue function. In a follow-up experiment, MDSC also survived and differentiated into myotubules after being injected into murine bladders [37].

Periurethral or transurethral injection of MDSC has been shown to be a possible treatment for SUI. In rats with denervated and atrophied urethras, periurethral injection of MDSC resulted in improvements in fast-twitch muscle contraction to $87 \%$ of the muscle contraction seen in control animals [38]. In addition, there was minimal immunohistochemical evidence of inflammation, despite the presence of a significant amount of skeletal muscle fiber formation. Similarly, periurethral injection of MDSC in rats improved leak point pressures in denervated rats [39]. Compared with both control and sham injected rats, those injected with MDSC had higher leak point pressures at 1 week $(25.2 \pm 1.9,28.6 \pm 0.8$, and $36.7 \pm 2.3$ $\mathrm{cmH}_{2} \mathrm{O}$, for control, sham, and MDSC injected rats, respectively) and 4 weeks $\left(25.8 \pm 2.5,18.6 \pm 5.2,44.1 \pm 6.6 \mathrm{~cm} \mathrm{H}_{2} 0\right.$, respectively). Histological examination of the MDSC injected rats revealed that the muscle fibers had variable orientation highlighting that injection likely served as a bulking agent as opposed to becoming a normal layer of the urethra. However, in a follow-up study, denervated rats were periurethrally injected with either MDSC or fibroblasts to determine if MDSC add additional benefits other than just bulking [40]. Denervated rats were either injected with saline, MDSC, fibroblasts, or a MDSC-fibroblast 50:50 mixture. Injection of MDSC significantly improved fast-twitch muscle contraction amplitude to $73 \%$ of normal while fibroblast injection only improved it to $46 \%$ of normal. Thus, the authors propose that the mechanism of benefit is different between MDSC and fibroblasts. Indeed, rats injected with fibroblasts also had a higher connective tissue mass at the injection site, highlighting that this may have more of a bulking effect.

In one of the only studies in humans, Carr et al. treated eight women with urodynamic-proven SUI [41••]. Autologous MDSC were obtained from thigh biopsy and transurethrally injected in up to four circumferential locations. Three women withdrew from the study after 1 month of follow-up; the remaining five all demonstrated improvement in stress incontinence as determined by pad tests and bladder diaries. The initial onset of improvement was between 3 to 8 months after injection, suggesting that the mechanism of action was improving muscle function as opposed to providing bulking. However, two individuals needed additional injections to achieve improvement and two went on to have midurethral slings placed. There were no reported adverse events. One other large human study involving periurethral injection has subsequently been retracted [42].

\section{Stress Urinary Incontinence and Adipose Tissue-Derived Stem Cells}

Adipose tissue-derived stem cells (ADSC) have been studied recently for lower urinary tract dysfunction given their easy accessibility and overall abundance [43, 44]. ADSC have been shown to differentiate into myoblasts and these myoblasts have subsequently been injected in to both the bladder smooth muscle and urethra. In a study by Fu et al., ADSC were obtained from 20 female rats with SUI and then induced ex vivo into myoblasts [45]. The myoblasts were then injected periurethrally with a microinjector into the urethral sphincter muscularis in the proximal urethra in ten of the animals; the remaining ten animals had injection of undifferentiated ADSC. To obtain leak point pressures, anesthetized animals underwent placement of an epidural catheter attached to an urodynamics flowmeter through a two centimeter cystotomy. At half-bladder capacity, increasing external pressure was placed on the animal's abdomen until urine leaked; pressures were then measured. The average leak point pressure and the maximal bladder capacity at 3 months were higher in the group with myoblast implantation compared with the group with undifferentiated ADSC $(41.12 \pm 2.89$ versus $32.52 \pm 2.16 \mathrm{cmH}_{2} 0$ and $2.09 \pm 0.09$ versus $1.88 \pm 0.05 \mathrm{cc}$, respectively). A similar study was done in 28 female rats with induced SUI; 12 rats were urethrally injected with ADSC while 6 rats were intravenously injected with ADSC [46]. Cystometry revealed that injection of ADSC either transurethrally or intravenously was associated with less voiding dysfunction compared with control animals (33.3\% versus $80 \%, p<0.05)$ as well as significantly lower leak point pressures. Histologic analysis revealed rats injected with ADSC had higher elastin content than controls. Although the authors were unable to quantify how 
much of the intravenous ADSC were present in the urethra, with the use of 5-bromo-2-deoxyuridien labeled-ADSC, they were able to demonstrate migration of the intravenous cells to the urethra. Thus, the authors highlight the potential tracking of intravenously injected ADSC to the urethra as yet another area of future research.

\section{Urge Urinary Incontinence and Stem Cells}

Much less is known about the potential benefits of stem cell therapy on UUI. Huang et al. specifically studied ADSC in rats with overactive bladder [47॰]. Thirty male rats were fed high-fat diets to decrease bladder blood flow with resultant denervation and ultimately detrusor overactivity; ten rats fed regular diets served as controls. Rats were then either injected in the detrusor with saline or autologous ADSC or had injection of ADSC into the tail vein. Among rats with overactive bladder, those treated with intradetrusor ADSC had longer micturition intervals $(368 \pm 66.8$ seconds versus $143 \pm 28.7$ seconds, $p<0.01)$ and greater mean volume per void $(0.628 \pm 0.122 \mathrm{~mL}$ versus $0.23 \pm 0.05 \mathrm{~mL}, p<0.01)$ compared with saline injected rats. Histologic data demonstrated improvement in microvessel and neuronal content of the detrusor muscle. Given the limited available data on stem cell therapy and urge incontinence, significantly more study is needed to determine if stem cells may be a potential treatment option.

\section{Concerns with Stem Cells}

Aside from the ethical issues discussed earlier, other major concerns with stem cell technology exist. The true risks of stem cell therapies remain undefined but may include complications as a result of overproduction with resultant neoplasia and migration. These complications likely will not be fully appreciated until more research in humans has been completed. To date, most cell transplantation studies are performed in patients with dismal prognoses (end-stage diabetes, advanced neurodegenerative diseases, spinal cord injury and cardiac failure) and limited life expectancies. In contrast, women seeking treatment for incontinence, a quality of life issue, are relatively healthy and most anticipate a normal life expectancy. Thus, in theory, transplanted cells and their potential complications will be present for decades or longer.

\section{Concerns with Current Research}

While the past two decades have provided early encouraging results in the use of stem cells for treatment of urinary incontinence, the majority of the studies involved animal models only and had limited discussions about the possible mechanism of action or target populations. Various animal models for SUI are routinely used, yet all cannot completely capture the complex process of micturition and urinary leakage, and thus rely on surrogate markers such as leak point pressures [48]. Similarly, it is impossible to capture intent in animals so the behavioral component of continence cannot be ascertained [49]. Lastly, animals often have to be anesthetized for advanced urologic testing adding additional sources of confounding. Thus, although research in animals is necessary, it is unclear how promising results with stem cell therapy will translate into human use.

Perhaps the most basic tenant of regenerative medicine is to define the basic pathophysiology of the problem needing repair. Unfortunately, the mechanism by which the urethral sphincters maintain continence is not well understood. Similarly, the available studies give limited explanations of how stem cell therapy improves continence. Theories thus far have included periurethral bulking alone, improvement in sphincter muscle or surrounding tissue function, and promotion of innervation $[36,41 \bullet \cdot$. A more thorough understanding of both the pathophysiology of incontinence and in the potential mechanisms of action of stem cells is needed. Lastly, the phenotype of the target population is not clearly defined. Ideal candidates for stem cell therapy include those with urethral hypomotility, a low-pressure urethra (i.e., maximal urethral closure pressure less than $20 \mathrm{~cm} \mathrm{H}_{2} 0$ ), those who have failed previous incontinence surgery, the elderly, and those with mesh intolerance.

New technologies are extremely appealing to all involved: enthusiastic scientists, ambitious clinicians, and industry eager for commercial gain. Such a combination creates a potentially dangerous scenario in which a patient desperate to improve her condition becomes an easy target for unforeseen complications in the event that the technology is introduced too quickly and without good scientific evidence or oversight. Thus, clear goals and expectations and thorough understanding of therapy is crucial for patient safety.

\section{Conclusions}

Currently available treatment options for both stress and urge urinary incontinence have variable efficacies and potential adverse events, and thus there is a need for novel treatment options that may ultimately provide better outcomes at lower risks. Preliminary studies with stem cells in mostly animal models have shown this is a promising area for future research and may indeed eventually yield the ideal therapy for stress or urge incontinence. However, substantial research must be done specifically focusing on pathophysiology, 
mechanism of action, and safety before routinely offering this therapy.

\section{Compliance with Ethics Guidelines}

Conflict of Interest Kelly L. Kantartzis declares that she has no conflict of interest.

Pamela A. Moalli declares that she has no conflict of interest.

Human and Animal Rights and Informed Consent This article does not contain any studies with human or animal subjects performed by any of the authors.

\section{References}

Papers of particular interest, published recently, have been highlighted as:

\section{- Of importance}

-. Of major importance

1. Sims J, Browning C, Lundgren-Lindquist B, et al. Urinary incontinence in a community sample of older adults: prevalence and impact on quality of life. Disabil Rehabil. 2011;33: 1389-98.

2. Sexton CC, Coyne KS, Thompson C, et al. Prevalence and effect on health-related quality of life of overactive bladder in older americans: results from the epidemiology of lower urinary tract symptoms study. J Am Geriatr Soc. 2011;59:1465-70.

3. Luber KM. The definition, prevalence, and risk factors for stress urinary incontinence. Rev Urol. 2004;6 Suppl 3:S3-9.

4. Hu TW, Wagner TH, Bentkover JD, et al. Costs of urinary incontinence and overactive bladder in the United States: a comparative study. Urology. 2004;63:461-5.

5. Wu JM, Kawasaki A, Hundley AF, et al. Predicting the number of women who will undergo incontinence and prolapse surgery, 2010 to 2050. Am J Obstet Gynecol. 2011;205:230 e1-5.

6. Bent AE. Urethral injection of bulking agents for intrinsic sphincter deficiency. In: Walters MD, Karram MM, editors. Urogynecology and reconstructive pelvic surgery. Philadelphia: Mosby Elsevier; 2007. p. 227-33.

7. Dmochowski RR, Appell RA. Injectable agents in the treatment of stress urinary incontinence in women: where are we now? Urology. 2000;56:32-40.

8. Pannek J, Brands FH, Senge T. Particle migration after transurethral injection of carbon coated beads for stress urinary incontinence. J Urol. 2001;166:1350-3.

9. Richter HE, Albo ME, Zyczynski HM, et al. Retropubic versus transobturator midurethral slings for stress incontinence. N Engl J Med. 2010;362:2066-76.

10. Novara G, Galfano A, Boscolo-Berto R, et al. Complication rates of tension-free midurethral slings in the treatment of female stress urinary incontinence: a systematic review and meta-analysis of randomized controlled trials comparing tension-free midurethral tapes to other surgical procedures and different devices. Eur Urol. 2008;53:288-308

11. Sears CL, Lewis C, Noel K, et al. Overactive bladder medication adherence when medication is free to patients. J Urol. 2010;183:1077-81

12. Brubaker L, Richter HE, Visco A, et al. Refractory idiopathic urge urinary incontinence and botulinum A injection. J Urol. 2008;180:217-22.
13. Sahai A, Khan MS, Le Gall N, et al. Urodynamic assessment of poor responders after botulinum toxin-A treatment for overactive bladder. Urology. 2008;71:455-9.

14. Brazzelli M, Murray A, Fraser C. Efficacy and safety of sacral nerve stimulation for urinary urge incontinence: a systematic review. J Urol. 2006;175:835-41.

15. Peters KM, Carrico DJ, Perez-Marrero RA, et al. Randomized trial of percutaneous tibial nerve stimulation versus Sham efficacy in the treatment of overactive bladder syndrome: results from the SUmiT trial. J Urol. 2010;183:1438-43.

16. Tincello DG, Kenyon S, Abrams KR, et al. Botulinum toxin a versus placebo for refractory detrusor overactivity in women: a randomised blinded placebo-controlled trial of 240 women (the RELAX study). Eur Urol. 2012;62:507-14.

17. Sahai A, Dowson C, Khan MS, et al. Repeated injections of botulinum toxin-A for idiopathic detrusor overactivity. Urology. 2010;75:552-8.

18. Groen J, Blok BF, Bosch JL. Sacral neuromodulation as treatment for refractory idiopathic urge urinary incontinence: 5 -year results of a longitudinal study in 60 women. J Urol. 2011;186:954-9.

19. White WM, Mobley 3rd JD, Doggweiler R, et al. Incidence and predictors of complications with sacral neuromodulation. Urology. 2009;73:731-5

20. van Kerrebroeck PE, van Voskuilen AC, Heesakkers JP, et al. Results of sacral neuromodulation therapy for urinary voiding dysfunction: outcomes of a prospective, worldwide clinical study. J Urol. 2007;178:2029-34.

21. Hassouna MM, Siegel SW, Nyeholt AA, et al. Sacral neuromodulation in the treatment of urgency-frequency symptoms: a multicenter study on efficacy and safety. J Urol. 2000;163:1849-54.

22. Ulloa-Montoya F, Verfaillie $\mathrm{CM}, \mathrm{Hu}$ WS. Culture systems for pluripotent stem cells. J Biosci Bioeng. 2005;100:12-27.

23. Thomson JA, Itskovitz-Eldor J, Shapiro SS, et al. Embryonic stem cell lines derived from human blastocysts. Science. 1998;282:1145-7.

24. Landry DW, Zucker HA. Embryonic death and the creation of human embryonic stem cells. J Clin Invest. 2004;114:1184-6.

25. Zhang X, Stojkovic P, Przyborski S, et al. Derivation of human embryonic stem cells from developing and arrested embryos. Stem Cells. 2006;24:2669-76.

26. Joo S, Ko IK, Atala A, et al. Amniotic fluid-derived stem cells in regenerative medicine research. Arch Pharm Res. 2012;35:271-80.

27. Bongso A, Fong CY. The therapeutic potential, challenges and future clinical directions of stem cells from the Wharton's jelly of the human umbilical cord. Stem Cell Rev. 2013;9:226-40.

28. da Silva Meirelles L, Chagastelles PC, Nardi NB. Mesenchymal stem cells reside in virtually all post-natal organs and tissues. J Cell Sci. 2006;119:2204-13.

29. •- Shokeir AA, Harraz AM, El-Din AB. Tissue engineering and stem cells: basic principles and applications in urology. Int J Urol. 2010;17:964-73. This review highlights basic understanding of stem cell thearpy while also giving a comprehensive overview of stem cell therapy in multiple urologic disorders.

30. Kirchin V, Page T, Keegan PE, et al. Urethral injection therapy for urinary incontinence in women. Cochrane Database Syst Rev. 2012;2:CD003881.

31. Bent AE, Tutrone RT, McLennan MT, et al. Treatment of intrinsic sphincter deficiency using autologous ear chondrocytes as a bulking agent. Neurourol Urodyn. 2001;20:157-65.

32. Mitterberger M, Pinggera GM, Marksteiner R, et al. Adult stem cell therapy of female stress urinary incontinence. Eur Urol. 2008;53:169-75.

33. Mitterberger M, Marksteiner R, Margreiter E, et al. Autologous myoblasts and fibroblasts for female stress incontinence: a 1-year follow-up in 123 patients. BJU Int. 2007;100:1081-5.

34. Chancellor MB, Yokoyama T, Tirney S, et al. Preliminary results of myoblast injection into the urethra and bladder wall: a possible method for the treatment of stress urinary incontinence and impaired detrusor contractility. Neurourol Urodyn. 2000;19:279-87. 
35. Beauchamp JR, Morgan JE, Pagel CN, et al. Dynamics of myoblast transplantation reveal a discrete minority of precursors with stem celllike properties as the myogenic source. J Cell Biol. 1999;144:1113-22.

36. Yokoyama T, Yoshimura N, Dhir R, et al. Persistence and survival of autologous muscle derived cells versus bovine collagen as potential treatment of stress urinary incontinence. J Urol. 2001;165:271-6.

37. Yokoyama T, Huard J, Pruchnic R, et al. Muscle-derived cell transplantation and differentiation into lower urinary tract smooth muscle. Urology. 2001;57:826-31.

38. Cannon TW, Lee JY, Somogyi G, et al. Improved sphincter contractility after allogenic muscle-derived progenitor cell injection into the denervated rat urethra. Urology. 2003;62:958-63.

39. Lee JY, Cannon TW, Pruchnic R, et al. The effects of periurethral muscle-derived stem cell injection on leak point pressure in a rat model of stress urinary incontinence. Int Urogynecol J Pelvic Floor Dysfunct. 2003;14:31-7. discussion 37.

40. Kwon D, Kim Y, Pruchnic R, et al. Periurethral cellular injection: comparison of muscle-derived progenitor cells and fibroblasts with regard to efficacy and tissue contractility in an animal model of stress urinary incontinence. Urology. 2006;68:449-54.

41. • Carr LK, Steele D, Steele S, et al. 1-year follow-up of autologous muscle-derived stem cell injection pilot study to treat stress urinary incontinence. Int Urogynecol J Pelvic Floor Dysfunct. 2008;19:881-3. This small study includes eight women who received transurethral injection of autologous muscle-derived stem cells and is one of the few studies in humans and demonstrated that injection may be effective with minimal risk.

42. Strasser H, Marksteiner R, Margreiter E, et al. Autologous myoblasts and fibroblasts versus collagen for treatment of stress urinary incontinence in women: a randomised controlled trial. Lancet. 2007;369:2179-86.

43. Lin CS. Advances in stem cell therapy for the lower urinary tract. World J Stem Cells. 2010;2:1-4.

44. Strem BM, Hicok KC, Zhu M, et al. Multipotential differentiation of adipose tissue-derived stem cells. Keio J Med. 2005;54:132-41.

45. Fu Q, Song XF, Liao GL, et al. Myoblasts differentiated from adipose-derived stem cells to treat stress urinary incontinence. Urology. 2010;75:718-23.

46. Lin G, Wang G, Banie L, et al. Treatment of stress urinary incontinence with adipose tissue-derived stem cells. Cytotherapy. 2010;12:88-95.

47. • Huang YC, Shindel AW, Ning H, et al. Adipose derived stem cells ameliorate hyperlipidemia associated detrusor overactivity in a rat model. J Urol. 2010;183:1232-40. This is one of the few studies to assess stem cell therapy for urge urinary incontinence and provided preliminary evidence that in a rat model, adispoe derived stem cells may improve micutition frequency and volume voided.

48. Hijaz A, Daneshgari F, Sievert KD, et al. Animal models of female stress urinary incontinence. J Urol. 2008;179:2103-10.

49. Jiang HH, Damaser MS: Animal models of stress urinary incontinence. Handb Exp Pharmacol 2011;45-67. 